\title{
Current diagnosis and treatments for critical congenital heart defects (Review)
}

\author{
ZHANDONG ZENG, HONGWEI ZHANG, FENGLI LIU and NING ZHANG \\ Department of Pediatric Surgery, Xuzhou Children's Hospital, Xuzhou, Jiangsu 221002, P.R. China
}

Received January 29, 2016; Accepted March 15, 2016

DOI: $10.3892 /$ etm.2016.3167

\begin{abstract}
Congenital heart defects (CHD) affect approximately $7 \%$ of infants, and account for $3 \%$ of all infant deaths. CHD is most often caused by the defects associated with ductus arteriosus, which is a vessel that usually closes shortly after birth. The types of CHD include tetralogy of fallot, hypoplastic left heart syndrome, pulmonary atresia, total anomalous pulmonary venous return, transposition of great arteries, tricuspid atresia and truncus arteriosus. There are some risk factors that can increase the chance of a fetus developing CHD such as prematurity, an existing CHD in a first-degree relative, genetic syndromes, infections in utero, maternal drug consumptions and disorders. CHD is diagnosed is through different techniques including pulse oximetry, echocardiograms and physical exams. In this review, we examined the current incidence of $\mathrm{CHD}$, the risk factors associated with $\mathrm{CHD}$, the current methods of diagnosis and surgical options used to repair the defects.
\end{abstract}

\section{Contents}

1. Epidemiology

2. Pathology

3. Risk factors

4. Diagnosis

5. The CHD model: screens and costs

6. Pulse oximetry screen

7. Fetal echocardiogram

8. Clinical examination

9. CHD surgery: patent ductus arteriosus (PDA) ligation

10. CHD surgery: coarctation of the aorta repair

11. CHD surgery: atrial and VSD repair

12. CHD surgery: tetralogy of fallot repair

Correspondence to: Dr Fengli Liu, Department of Pediatric Surgery, Xuzhou Children's Hospital, 18 Sudibei Road, Xuzhou, Jiangsu 221002, P.R. China

E-mail: ieswt61@163.com

Key words: congenital heart defects, pulmonary atresia, tricuspid atresia, truncus arteriosus
13. CHD surgery: transposition of the great vessels repair

14. CHD surgery: truncus arteriosus and tricuspid atresia repair

15. CHD surgery: TAPVR and hypoplastic left heart repair 16. Conclusion

\section{Epidemiology}

The incidence of congenital heart disease ranges from 7 to 8 per 1,000 infants. These defects are diagnosed through different techniques such as fetal echocardiography and postnatal referral to a specialized center. Forty-six percent of deaths due to congenital malformations are due to congenital heart defects (CHD), which also accounts for 3\% of all infant deaths. CHD is the primary cause of prenatal and infant death from a congenital birth defect. Eighteen to $25 \%$ of infants with CHD succumb in the first year. Four percent of infants with congenital heart defects succumb by the end of adolescence $(1,2)$.

There are different types of CHD, the most common of which is a bicuspid aortic valve (BAV). The incidence of BAV is between 0.5 and $2 \%$, however, it is rarely diagnosed when the child is an infant. Some of the other common defects include ventricular septal defects (VSDs), with an incidence of 4/1,000 and secundum atrial septal defects (ASDs) with an incidence of 2/1,000 births. Tetralogy of fallot is another common CHD, with an incidence of $0.5 / 1,000$ births $(1,3)$.

When CHD requires surgery or catheter-based intervention in the first year of an infant's life, it is termed critical CHD (CCHD). CCHD includes ductal-dependent and cyanotic lesions. In children with critical CHD, there is an increase in morbidity and mortality when the infant is not diagnosed within a particular period of time. CCHD constitutes $25 \%$ of all CHD (4).

\section{Pathology}

The ductus arteriosus is a blood vessel that connects the aorta and the pulmonary arteries during gestation (5). The fetal blood circulation is dependent on this blood vessel, which normally closes shortly after birth. CHD issues are usually dependent on this vessel. Symptoms may not appear at birth due to the fact that the vessel may not be closed before the patient is discharged. Notably, in some cases doctors attempt to keep the ductus arteriosus open in order that children with 
CHD can maintain oxygen levels until surgeons are able to repair the issue. An example of such a case is if the CHD decreased blood flow to the lungs. CCHD involves surgery or catheter intervention in the first year of life. These heart defects, which are structural, lead to abnormal low blood levels of oxygen. When there are low blood oxygen levels, the condition is known as hypoxemia. Screening for these issues is carried out between 24 and $48 \mathrm{~h}$ post-birth. If these conditions are diagnosed any later, the infant with CCHD is at considerable risk for death $(6,7)$.

\section{Risk factors}

Numerous factors, such as rubella infection at the time of pregnancy, maternal diabetes, use of alcohol and smoking, as well as certain medications are associated with an increase in the risk of CHD in infants (7). When these factors are present, a doctor should be cautious and attentive to the infant. Prematurity is a significant risk factor for all CHD, except isolated ductus arteriosus. The risk of CHD is 2- to 3-fold higher in infants born at $<37$ weeks gestation when compared to infants born at 9 months. Family history is another risk factor for CHD. Infants with first-degree relatives with CHD are three times more likely to develop CHD. Genetic syndromes are common in infants with CHD. In one study, it was found that $7 \%$ of infants with CHD also had chromosomal defects. In addition, $22 \%$ of patients with CHD had extracardiac anomalies (8). Another risk factor for CHD is when the mother has certain diseases. These diseases include diabetes mellitus, hypertension, obesity, phenylketonuria, thyroid issues, epilepsy and connective tissue disorders. Furthermore, consumption of drugs by the mother during the gestation period such as phenytoin, retinoic acid, cigarettes and alcohol, it can lead to cardiac defects. Using assisted reproductive technology (ART) is another risk factor for CHD. Infections in utero, such as rubella, can also lead to congenital defects. If the mother, when pregnant, is infected with influenza or another flu-type disease, this is also associated with CHD. Viruses such as cytomegalovirus, coxsackie, herpes virus 6 , toxoplasmosis gondii, parvovirus B19 and HIV may also lead to congenital cardiomyopathy (9-11).

\section{Diagnosis}

Most of the time clinicians, using fetal echocardiography, are able to diagnose CHD in utero. Risk factors need to be identified promptly in order that a referral can be made for fetal echocardiography, which is a routine antenatal ultrasound. This method includes examination of the fetal heart with a four-chamber view. However, studies in the last decade have indicated that $<50 \%$ of patients with CCHD are identified in utero. There are seven main CCHD screening targets. These targets are hypoplastic left heart syndrome, pulmonary atresia, tetralogy of fallot, total anomalous pulmonary venous return (TAPVR), transposition of great arteries, tricuspid atresia and truncus arteriosus. Tetralogy of fallot, double outlet right ventricle and transposition of the great arteries are particular difficult to identify. As research and screening recommendations have improved over the past decade, VCHD diagnoses in gestation have improved from 44 to $67 \%(12,13)$.
A study (14) found that $33 \%$ of infants with critical CHD were diagnosed post-birth. These infants often have very serious issues, such as tetralogy of fallot, hypoplastic left heart syndrome, pulmonary atresia, total anomalous pulmonary venous return, transposition of great arteries, tricuspid atresia and truncus arteriosus, which can be life threatening and may need immediate intervention. Infants with CCHD may present no problems at birth and may not develop problems until they have been discharged from the hospital. The severity of the underlying lesions may determine when an infant with CCHD presents symptoms. Some of the CCHD reported later than normal are interrupted aortic arch, coarctation of the aorta, transposition of the great arteries, pulmonary valve stenosis, tetralogy of fallot and aortic stenosis. Some infants with CCHD can be diagnosed through a procedure known as pulse oximetry screening. Prior to the introduction of pulse oximetry screening, a third of patients with infants with CCHD were discharged without a diagnosis. In an infant with CCHD that is not diagnosed, the mortality risk is almost $30 \%$. This constituted a risk to infants with ductal-dependent lesions, which can rapidly progress to a life-threatening state such as severe metabolic acidosis, cardiac arrest and cardiac shock $(15,16)$.

\section{The CHD model: screens and costs}

It is predicted that in a population of 100,000 infants, 121 infants are likely to have CHD that was not diagnosed at prenatal screening (17). Post-birth, $82 \%$ of the CHD are detected by pulse oximetry screening and $83 \%$ are diagnosed by an echocardiography. However, only $39 \%$ of CHD are detected by clinical examination. Only $0.13 \%$ of infants with pulse oximetry are also diagnosed false-positive following screening for CHD. In addition, 5.4\% of infants have a false-positive diagnosis when screened for CHD by echocardiography. While these procedures are necessary for the timely diagnosis of CHD in infants, these procedures are expensive. Clinical examinations cost $\$ 450,000$, pulse oximetry costs $\$ 700,000$ and echocardiography costs $\$ 5.35$ million per year. The detection rates of pulse oximetry and echocardiography are the key characteristics that determine whether these procedures are cost-effective $(18,19)$.

\section{Pulse oximetry screen}

A pulse oximetry screen is performed on an infant within the first $24 \mathrm{~h}$ of life, and can easily and quickly determine whether an infant has CCHD. This procedure was developed in the early 1970s, and is dependent on the different absorption spectrum that exists between oxygenated and deoxygenated hemoglobin. Deoxygenated blood absorbs light in the red wavelength while oxygenated blood absorbs light in the infrared band. These light absorbance ratios correlate with the degree of saturation of hemoglobin in the blood vessels. A positive pulse oximetry screen is when the measured oxygen saturation is less than $90 \%$ and there is no need to repeat the test. If the blood saturations is $<95 \%$ or if there is a difference in blood oxygen level of $\geq 4 \%$ between the right hand and foot, the test should be repeated. Pulse oximetry screening does not identify all CCHD. Therefore, it is possible for an infant with a negative pulse oximetry screening to have CCHD (19-21). 


\section{Fetal echocardiogram}

A fetal echocardiogram is an ultrasound of the baby's heart during gestation. A transducer, which is a small camera, is placed on the abdomen of the mother and ultrasonic sound waves allow the fetus to be imaged. These ultrasound waves bounce off organs, such as the heart and are transmitted to the camera and allow a video of the fetus. These waves also allow for the blood flow to the fetus's heart to be detected. Fetal echocardiograms are carried out particularly for fetuses that are more prone to develop CCHD. This includes risk factors such diagnosis of a first-degree relative with CHD or if there is a family history of disorders such Marfan's syndrome. Echocardiograms are also performed post-birth if an infant is tested positive for the pulse oximetry screen, which is used to confirm the diagnosis $(19,22,23)$.

\section{Clinical examination}

A physical clinical examination is performed by a child's doctor when a heart condition is suspected. This involves a head-to-toe assessment. The doctor initially examines the head checking the anterior fontanelle, which is also known as the soft spot on the top of an infant's head. The anterior fontanelle is usually flat, soft and level with the rest of the head. The nostrils are also examined as many CHD can stress the lungs, which lead to difficulty in breathing. The degree of difficulty when it comes to breathing can be determined by observing whether the nostrils flare when the child breathes. Nostrils tend to open wider when the lungs are working harder than normal. Lip color is another characteristic used to determine whether a child has CHD (23). While normally the inside of the lips are pink, a blue or a purple color mean that the blood oxygen levels are low, generally between 80 and $87 \%$. As low blood oxygen levels indicate CHD, lip color is a useful manner in which to determine the presence of a defect in an infant. The doctor also examines the neck. If the veins and arteries are visible in the neck, the heart may not be pumping efficiently.

Using a stethoscope, the doctor also listens to the heart and lungs of the infant. One of the most telling signs for an infant with CHD is retraction, which is an inward pulling of the lung muscles. Additionally, any abnormal sounds may indicate murmurs, clicks and beats. Abnormal sounds may also be present in the lungs, as fluid can accumulate and cause crackletype noises or congestion sounds. The heart and breathing rates are counted as a difference in either is indicative the presence of CHD. Examination of the abdomen is important as many CHD cause problems with water homeostasis and cause swelling in organs such as the liver. An enlarged liver is indicative of CHD. The arms and legs, as well as the area around the groin, behind the knee or surface of the foot are examined for a pulse. A weak and a strong pulse may indicate heart problems. Cool skin temperature, as well as extremely blue or purple or widened nails are other symptoms that are considered $(24,25)$.

\section{CHD surgery: patent ductus arteriosus (PDA) ligation}

When the PDA does not close in infants, it can cause problems later in life. The opening may be closed using medication, although administering drugs is not always effective. The opening may also be closed using a non-surgical procedure, involving the use of X-rays. In the surgical procedure, a small incision is made in the groin and a wire is inserted into an artery in the leg and taken up to the heart. A device, which is sometimes a small metal coil, is then passed from the wire to the infant's PDA. This device blocks the blood flow and repairs the damage. Another surgical method to repair PDA is by making a small incision on the left side of the chest. Then, the doctor either ties or clips the ductus arteriosus, known as ligation $(25,26)$.

\section{CHD surgery: coarctation of the aorta repair}

One of the congenital heart defects occurs when a part of the aorta has an extremely narrow section and resembles a bow. The narrowing makes it hard for the blood to be pumped to the extremities, which can eventually lead to extremely high BP (27). This is repaired surgically by making an incision on the left side of the chest, cutting the narrow section and making it larger with a patch of Gore-tex. Another technique that can be employed involves the removal of the narrow section of the aorta and stitching the ends together, a method used in older children (28). Another method involves the subclavian flap, in which an incision is made in the narrow sectino. Subsequently, a section is taken from the subclavian artery and placed therein to enlarge the aorta. Connecting the enlarged sections of the aorta, which bypasses the narrow part of the aorta may also be utilized. A non-surgical method has also recently been used whereby a wire is taken up to the aorta through the groin. A stent is placed to open the artery, similar to the ones that are used for atherosclerosis $(29,30)$.

\section{CHD surgery: atrial and VSD repair}

In some CHD, there is a hole in the atrial septum wall, which is located between the left and right atria of the heart. This hole leads to the mixing of oxygenated and deoxygenated blood, which leads to medical issues and arrhythmias. In some cases, ASD can be closed without open-heart surgery. In this procedure, a wire is inserted into the groin and into the blood vessel that leads to the heart. Two small devices are placed on the right and left side of the septum, which closes the hole. More commonly, open-heart surgery is used to repair ASD. In this case, stitching the hole together or covering it with a patch repairs the septum $(31,32)$.

Another similar CHD is a VSD, which is a hole between the left and right ventricle of the heart. This hole, once again, allows the mixing of the oxygenated and deoxygenated blood, which eventually leads to heart problems. In most cases, the VSDs close by age 1 . The ones that do not close require repair. Open-heart surgery is performed when a child has a large VSD, a small one in a certain part of the ventricular septum, or a hole that may cause heart failure or inflammation $(33,34)$.

\section{CHD surgery: tetralogy of fallot repair}

Tetralogy of fallot refers to a heart defect that involves four defects and leads to cyanosis (35). The infant with this type of CHD requires open-heart surgery that can be performed between the age of 6 months and 2 years. A shunt procedure 
may also be performed, which is useful in keeping oxygenated and deoxygenated blood separate. This is carried out when the child is unable to undergo open-heart surgery as placing a shunt occurs prior to performing open-heart surgery. The first defect that is repaired is the VSD, using a patch. Subsequently, the pulmonary valve is opened and the thickened muscle removed. In addition, a patch is placed on the right ventricle and the pulmonary artery improves blood flow to the lungs $(36,37)$.

\section{CHD surgery: transposition of the great vessels repair}

Transposition of the great vessels, another CHD, occurs when instead of the aorta being located on the left side and the pulmonary artery on the right side, the sides for the two are switched (38). Since this needs to be resolved immediately, the open-heart surgery required is performed shortly after birth. Repair takes the form of an arterial switch, which involves the aorta and pulmonary artery being divided. The pulmonary artery and aorta are then connected to the ventricles to which they belong (39).

\section{CHD surgery: truncus arteriosus and tricuspid atresia repair}

In truncus arteriosus, the aorta, coronary arteries and pulmonary artery emerge from a common trunk. Thus, repair of the truncus arteriosus can be simple or complex; however, each case requires open-heart surgery performed in the first few days of life. The arteries are separated from the aortic trunk and defects are subsequently repaired. This procedure may be accompanied with a VSD as well. A connection is then made between right ventricle and pulmonary arteries. Tricuspid atresia occurs when the tricuspid valve is deformed, narrow or absent. The symptoms of tricuspid atresia include newborns being blue, as they cannot get the blood to the lungs. This severely restricts blood flow to the lungs, causing an inability for the blood to gain oxygen. Initially, the infant may be given shunts to correct the defect and allow the blood to reach the lungs. However, the surgeon may have to repair or replace the tricuspid valve $(40,41)$.

\section{CHD surgery: TAPVR correction and hypoplastic left heart repair}

Total anomalous pulmonary venous return (TAPVR) is a misconnection (42). Instead of the pulmonary veins bringing oxygenated blood to the left side of the heart, it is taken to the right side of the heart. This condition is repaired with open-heart surgery, which is carried out shortly after birth in extreme conditions up to a maximum of six months of age. The pulmonary veins are re-routed to the left side and any abnormal connections are closed (43).

When the left side of the heart is poorly developed, this leads to a severe heart defect, which if left untreated, leads to death. The hypoplastic left heart requires hypoplastic left heart repair (44). Infants with hypoplastic left hearts require a series of three heart operations. The first one is a complicated surgery performed in the first week of the baby's life when one blood vessel, which carries blood to lungs and the rest of the body, is created from pulmonary artery and aorta.
The following operation is performed when the baby is aged 4-6 months and the third operation is performed a year later, i.e., three surgeries are required to correct the problem (45).

\section{Conclusion}

Critical congenital heart defects, when undiagnosed constitute a risk factor and have a $30 \%$ mortality rate if left untreated. Techniques for diagnosis including pulse oximetry, echocardiogram and physical examinations have really improved the detection rates for CHD and CCHD. Surgical procedures such as PDA ligation, coarctation of the aorta repair, ASD repair, VSD repair, tetralogy of fallot repair, transposition of the great vessels repair, truncus arteriosus repair, tricuspid atresia repair, TAPVR correction and hypoplastic left heart repair are performed to repair CHD, and have greatly improved the survival rate for infants born with CHD. New screening and new non-surgical methods are to be investigated to treat this condition as not all infants are in a position to undergo intensive surgery immediately following birth.

\section{References}

1. Hoffman JI, Kaplan S and Liberthson RR: Prevalence of congenital heart disease. Am Heart J 147: 425-439, 2004.

2. Marelli AJ, Mackie AS, Ionescu-Ittu R, Rahme E and Pilote L: Congenital heart disease in the general population: changing prevalence and age distribution. Circulation 115: 163-172, 2007.

3. Scharhag J, Meyer T, Kindermann I, Schneider G, Urhausen A and Kindermann W: Bicuspid aortic valve: evaluation of the ability to participate in competitive sports: case reports of two soccer players. Clin Res Cardiol 95: 228-234, 2006.

4. Arlettaz R, Bauschatz AS, Mönkhoff M, Essers B and Bauersfeld U: The contribution of pulse oximetry to the early detection of congenital heart disease in newborns. Eur J Pediatr 165: 94-98, 2006.

5. Rudolph AM and Heymann MA: The circulation of the fetus inutero. Methods for studying distribution of blood flow, cardiac output and organ blood flow. Circ Res 21: 163-184, 1967.

6. Freed MD, Heymann MA, Lewis AB, Roehl SL and Kensey RC: Prostaglandin E1 infants with ductus arteriosus-dependent congenital heart disease. Circulation 64: 899-905, 1981.

7. Hoffman JI and Kaplan S: The incidence of congenital heart disease. J Am Coll Cardiol 39: 1890-1900, 2002.

8. Presbitero P, Somerville J, Stone S, Aruta E, Spiegelhalter D and Rabajoli F: Pregnancy in cyanotic congenital heart disease. Outcome of mother and fetus. Circulation 89: 2673-2676, 1994.

9. Jenkins KJ, Gauvreau K, Newburger JW, Spray TL, Moller JH and Iezzoni LI: Consensus-based method for risk adjustment for surgery for congenital heart disease. J Thorac Cardiovasc Surg 123: 110-118, 2002.

10. Jenkins KJ, Correa A, Feinstein JA, Botto L, Britt AE, Daniels SR, Elixson M, Warnes CA and Webb CL; American Heart Association Council on Cardiovascular Disease in the Young: Noninherited risk factors and congenital cardiovascular defects: current knowledge: a scientific statement from the American Heart Association Council on Cardiovascular Disease in the Young: endorsed by the American Academy of Pediatrics. Circulation 115: 2995-3014, 2007.

11. Sun R, Liu M, Lu L, Zheng Y and Zhang P: Congenital heart disease: Causes, diagnosis, symptoms, and treatments. Cell Biochem Biophys: Feb 1, 2015 (Epub ahead of print).

12. Stoll C, Alembik Y, Roth MP, Dott B and De Geeter B: Risk factors in congenital heart disease. Eur J Epidemiol 5: 382-391, 1989.

13. Kleinman CS, Hobbins JC, Jaffe CC, Lynch DC and Talner NS: Echocardiographic studies of the human fetus: prenatal diagnosis of congenital heart disease and cardiac dysrhythmias. Pediatrics 65: 1059-1067, 1980.

14. Thangaratinam S, Brown K, Zamora J, Khan KS and Ewer AK: Pulse oximetry screening for critical congenital heart defects in asymptomatic newborn babies: A systematic review and metaanalysis. Lancet 379: 2459-2464, 2012. 
15. Carvalho JS, Mavrides E, Shinebourne EA, Campbell S and Thilaganathan B: improving the effectiveness of routine prenatal screening for major congenital heart defects. Heart 88: 387-391, 2002.

16. Koppel RI, Druschel CM, Carter T, Goldberg BE, Mehta PN, Talwar R and Bierman FZ: Effectiveness of pulse oximetry screening for congenital heart disease in asymptomatic newborns Pediatrics 111: 451-455, 2003.

17. van der Bom T, Zomer AC, Zwinderman AH, Meijboom FJ, Bouma BJ and Mulder BJ: The changing epidemiology of congenital heart disease. Nat Rev Cardiol 8: 50-60, 2011.

18. Andrea J: Implications of using pulse oximetry to screen for critical congenital heart disease in newborns. Nurs Womens Health 19: 314-323, 2015.

19. Griebsch I, Knowles RL, Brown J, Bull C, Wren C and Dezateux CA: Comparing the clinical and economic effects of clinical examination, pulse oximetry, and echocardiography in newborn screening for congenital heart defects: a probabilistic cost-effectiveness model and value of information analysis. Int J Technol Assess Health Care 23: 192-204, 2007.

20. Baumgartner H, Bonhoeffer P, De Groot NM, de Haan F, Deanfield JE, Galie N, Gatzoulis MA, Gohlke-Baerwolf C, Kaemmerer H, Kilner P, et al; Task Force on the Management of Grown-up Congenital Heart Disease of the European Society of Cardiology (ESC); Association for European Paediatric Cardiology (AEPC); ESC Committee for Practice Guidelines (CPG): ESC Guidelines for the management of grown-up congenital heart disease (new version 2010). Eur Heart J 31: 2915-2957, 2010

21. Sadeghian H and Savand-Roomi Z: Fetal heart echocardiography of twins. In: Echocardiographic Atlas of Adult Congenital Heart Disease 2015. Springer International Publishing, pp461-463, 2015.

22. Lee W, Allan L, Carvalho JS, Chaoui R, Copel J, Devore G, Hecher K, Munoz H, Nelson T, Paladini D, et al; ISUOG Fetal Echocardiography Task Force: ISUOG consensus statement: what constitutes a fetal echocardiogram? Ultrasound Obstet Gynecol 32: 239-242, 2008.

23. Bakr AF and Habib HS: Combining pulse oximetry and clinical examination in screening for congenital heart disease. Pediatr Cardiol 26: 832-835, 2005.

24. Kemper AR, Mahle WT, Martin GR, Cooley WC, Kumar P, Morrow WR, Kelm K, Pearson GD, Glidewell J, Grosse SD, et al: Strategies for implementing screening for critical congenital heart disease. Pediatrics 128: e1259-e1267, 2011

25. Mavroudis C and Backer C (eds): Patent ductus arteriosus ligation. In: Atlas of Pediatric Cardiac Surgery. Springer, London, pp35-43, 2015.

26. Gersony WM, Peckham GJ, Ellison RC, Miettinen OS and Nadas AS: Effects of indomethacin in premature infants with patent ductus arteriosus: results of a national collaborative study. J Pediatr 102: 895-906, 1983.

27. Zhao Q and $\mathrm{Hu} \mathrm{X}$ : Postoperative pulmonary hypertensivecrisis caused by inverted left atrial appendage after cardiopulmonary bypass surgery for congenital heart disease in a neonate. Heart Lung Circ 22: 781-783, 2013.

28. Langley SM, Sunstrom RE, Reed RD, Rekito AJ and Gerrah R: The neonatal hypoplastic aortic arch: Decisions and more decisions. Semin Thorac Cardiovasc Surg Pediatr Card Surg Annu 16: 43-51, 2013.
29. Toro-Salazar OH, Steinberger J, Thomas W, Rocchini AP, Carpenter B and Moller JH: Long-term follow-up of patients after coarctation of the aorta repair. Am J Cardiol 89: 541-547, 2002.

30. Knyshov GV, Sitar LL, Glagola MD and Atamanyuk MY: Aortic aneurysms at the site of the repair of coarctation of the aorta: a review of 48 patients. Ann Thorac Surg 61: 935-939, 1996.

31. Cheng TO: Atrial septal defect repair. Cleve Clin J Med 68: 174-174, 2001.

32. Murphy JG, Gersh BJ, McGoon MD, Mair DD, Porter CJ, Ilstrup DM, McGoon DC, Puga FJ, Kirklin JW and Danielson GK: Long-term outcome after surgical repair of isolated atrial septal defect. Follow-up at 27 to 32 years. N Engl J Med 323: 1645-1650, 1990.

33. Weirich W and Blevins W: Ventricular septal defect repair. Vet Surg 7: 2-7, 1978

34. Muehrcke DD, Daggett WM Jr, Buckley MJ, Akins CW, Hilgenberg AD and Austen WG: Postinfarct ventricular septal defect repair: effect of coronary artery bypass grafting. Ann Thorac Surg 54: 876-882, discussion 882-883, 1992.

35. Pacileo G, Musewe NN and Calabro R: Tetralogy of fallot in three siblings: A familial study and review of the literature. Eur J Pediatr 151: 726-727, 1992

36. Geva T, Sandweiss BM, Gauvreau K, Lock JE and Powell AJ: Factors associated with impaired clinical status in long-term survivors of tetralogy of Fallot repair evaluated by magnetic resonance imaging. J Am Coll Cardiol 43: 1068-1074, 2004.

37. Reddy VM, Liddicoat JR, McElhinney DB, Brook MM, Stanger P and Hanley FL: Routine primary repair of tetralogy of Fallot in neonates and infants less than three months of age. Ann Thorac Surg 60 (Suppl): S592-S596, 1995.

38. DeBord S, Cherry C and Hickey C: The arterial switch procedure for transposition of the great arteries. AORN J 86: 211-226, 2007.

39. Castaneda AR, Norwood WI, Jonas RA, Colon SD, Sanders SP and Lang P: Transposition of the great arteries and intact ventricular septum: anatomical repair in the neonate. Ann Thorac Surg 38: 438-443, 1984

40. Fontan F and Baudet E: Surgical repair of tricuspid atresia. Thorax 26: 240-248, 1971.

41. Lofland GK: Truncus arteriosus repair. In: Cardiac Reconstructions with Allograft Tissues. Springer-Verlag, New York, NY, pp530-543, 2005.

42. Wukasch DC, Deutsch M, Reul GJ, Hallman GL and Cooley DA: Total anomalous pulmonary venous return. Review of 125 patients treated surgically. Ann Thorac Surg 19: 622-633, 1975.

43. Kirshbom PM, Myung RJ, Gaynor JW, Ittenbach RF, Paridon SM, DeCampli WM, Karl TR and Spray TL: Preoperative pulmonary venous obstruction affects long-term outcome for survivors of total anomalous pulmonary venous connection repair. Ann Thorac Surg 74: 1616-1620, 2002.

44. Ugaki S, Khoo NS, Ross DB, Rebeyka IM and Adatia I: Tricuspid valve repair improves early right ventricular and tricuspid valve remodeling in patients with hypoplastic left heart syndrome. J Thorac Cardiovasc Surg 145: 446-450, 2013.

45. Norwood WI, Lang P and Hansen DD: Physiologic repair of aortic atresia-hypoplastic left heart syndrome. N Engl J Med 308: 23-26, 1983. 